\title{
Enhanced Plasticity of a Tool Steel Near $\alpha-\gamma$ Transformation
}

\author{
B. M. MOGUTNOV, N. V. PASETCHNIK' and E. I. ESTRIN
}

I.P.Bardin Central Research Institute for Ferrous Metallurgy, 9/23 $2^{\text {nd }}$ Baumanskaya St., Moscow 105005, Russia. E-mail: bmogutnov@mtu-net.ru 1) A.I.Tselikov All-Russian Design and Research Institute of Metallurgical Machinebuilding, 8A Ryazanskii Av. Moscow, 109428.

(Received on October 12, 2004; accepted on February 4, 2005)

\begin{abstract}
Phase transformations, high-temperature mechanical properties of a tool steel as well as its structure before and after rolling were studied with the aim of clarifying why high-carbon highly-alloyed steels can be rolled with rather high degrees of deformation at moderately low temperatures $\left(\sim 800^{\circ} \mathrm{C}\right)$. Three factors were found to bring the steel mechanical properties to the level that makes this type treatment possible. They are: 1) higher plasticity and lower strength of $\alpha$-phase as compared with $\gamma$-phase at the same temperature; 2) stability of the ferrite-carbide state up to temperatures exceeding $800^{\circ} \mathrm{C}$; 3) plasticity induced by $\alpha \rightarrow \gamma$ transformation in the process of rolling.

KEY WORDS: tool steels; microstructure; plasticity; strength; phase transformations; high-speed ohmic heating; TRIP effect.
\end{abstract}

\section{Introduction}

Difficult-to-form highly-alloyed high-carbon steels like tool steels are usually rolled above $1100-1150^{\circ} \mathrm{C} .{ }^{1,2)}$ Exposure to high temperature leads, as a rule, to uncontrolled grain growth, decarburizing and oxidizing the steel surface. Besides heating and protection from decarburization and oxidation are connected with substantial consumption of energy and considerable expenses.

An efficient technology of rolling was recently proposed $^{3,4)}$ that permits one-pass-deformation of tool steels with degrees of $25 \div 45 \%$ at significantly lower temperatures, approximately in the range of $780-800^{\circ} \mathrm{C}$. The technology is based on high-speed heating of difficult-to-roll steels by electric current of high intensity passing through the rolling billet just before it enters a roll mill stand. The power is supplied through a special feeding stand, installed several meters ahead of the rolling mill, and roughing rolls so that heating continues in the process of deformation. Hereafter this technique of heating will be referred to as the high-speed heating. The technology proposed in Refs. ${ }^{3,4)}$ is of considerable industrial interest because no problem outlined above appears, when steel is rolled at $780-800^{\circ} \mathrm{C}$.

Although growth in plasticity of steels in the range of 700 to $900^{\circ} \mathrm{C}$ was repeatedly observed, ${ }^{5-14)}$ true causes that offer the prospects of rolling of high-carbon highly-alloyed steels at moderately low temperatures remain unclear. A perspective way of gaining an insight into the regularities that make possible this type technology lies in an investigation of high-temperature mechanical properties and the effects of this treatment on the metal structure. The proximity of the rolling temperature to the interval of phase transitions connected with $\alpha \leftrightarrow \gamma$ transformation of iron suggests that there might be interrelation between these transitions and plasticity. Complex research of a tool steel was undertaken in the present work with the aim of elucidating the regularities that make possible the above technology of rolling.

\section{Materials and Experimental Procedures}

An industrial tool steel of the following composition (in $w t \%)$ was chosen for the research: $1.11 \mathrm{C}, 6.05 \mathrm{Cr}, 0.72 \mathrm{~V}$, $1.20 \mathrm{~W}, 0.16 \mathrm{Si}, 0.25 \mathrm{Mn}, 0.018 \mathrm{~S}$ and $0.02 \mathrm{P}$. Temperatures of phase transformations were determined using the dilatimeter ${ }^{15)}$ with an inductive transducer and flat specimens of $40 \times 4 \times 2 \mathrm{~mm}$ in size. Temperature was measured by a chromel-alumel thermocouple, the hot junction of which was in contact with the specimen. The rate of heating at the temperature range of phase transformations was $\sim 3^{\circ} \mathrm{C} / \mathrm{min}$. High-temperature tensile tests were carried out using a FP $100 / 1$ testing machine and standard specimens of $3.0 \mathrm{~mm}$ in diameter and of $30.0 \mathrm{~mm}$ in length of the working part. The strain rate was $\sim 2 \mathrm{~mm} / \mathrm{min}\left(\sim 10^{-2} \mathrm{~s}^{-1}\right)$, the holding time before the start of testing $\sim 3 \mathrm{~min}$.

Complex of experimental techniques was applied to study the structure of the steel in two states: 1) initial (after preliminary high-temperature annealing) and 2) after rolling, combined with the high-speed heating according to the above-mentioned technology, and air cooling. The metal in the initial state was in the form of plates $64 \mathrm{~mm}$ wide and $3.5 \mathrm{~mm}$ thick. One pass rolling reduced the thickness to 2 $\mathrm{mm}$ so that the deformation degree was $\sim 43 \%$. The conditions of rolling were as follows: temperature $-790^{\circ} \mathrm{C}$, rate $0.5 \mathrm{~m} / \mathrm{s}$, roll force $-700 \mathrm{kN}$. Microstructure was examined with a JEOL scanning electron microscope JSM-U3 and a JEM-7A electron microscope, transmission technique being used in the latter research. The microstructure of the rolled 

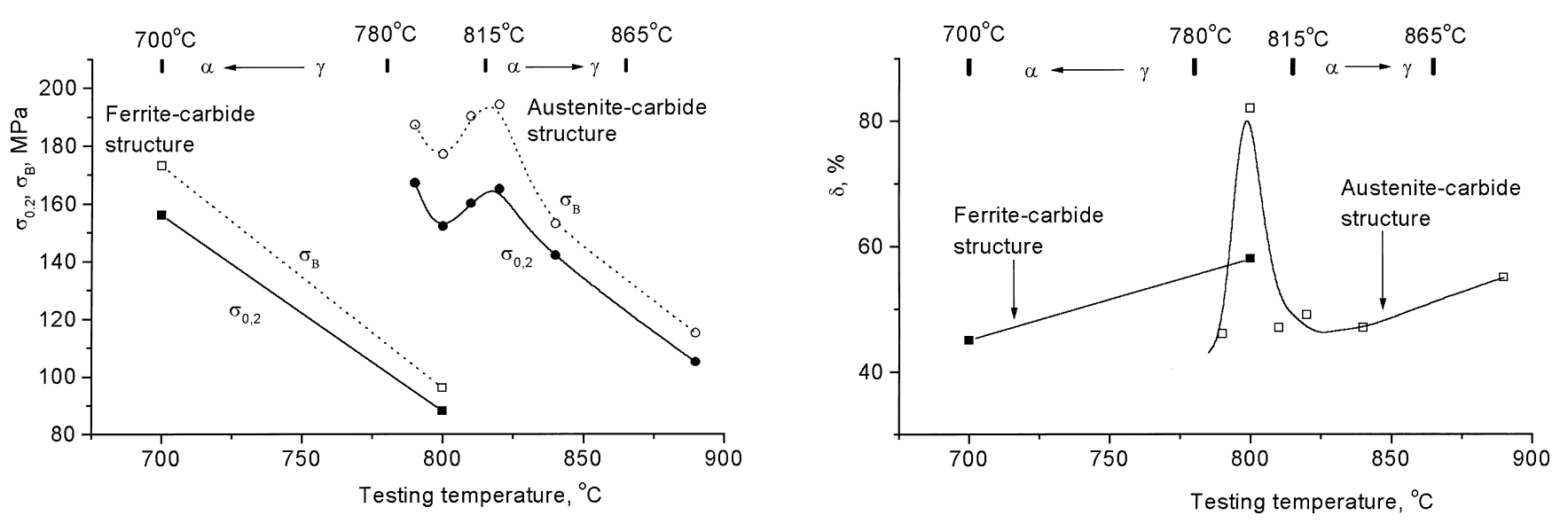

Fig. 1. High-temperature mechanical properties of the steel under study. a) Tensile strength $\left(\sigma_{\mathrm{B}}\right)$ and yield $\left(\sigma_{0.2}\right)$ stress: $\square$ and $\square$-ferrite-carbide structure, $\bigcirc$ and $\bigcirc$-austenite-carbide structure; b) relative elongation $(\delta)$ : $\mathbf{\square}$-ferrite-carbide structure, $\square$ - austenite-carbide structure.

steel was studied in the cross-section perpendicular to the rolling plane. The scanning microscope was also used for fractographic research. To prepare fracture surfaces, specimens of $30 \times 6 \times 2 \mathrm{~mm}$ with a sharp notch of $1 \mathrm{~mm}$ in depth were broken in two by an impact at room temperature in air. Scanning spectroscopy of Auger electrons was applied for chemical analysis of carbides. The spectrometer was equipped with the source of electron of the LEG200 type, the energy of primary electrons was $\sim 3000 \mathrm{eV}$ and the diameter of electron spot on specimens surface was approximately $200 \mathrm{~nm}$.

\section{Experimental Results}

\subsection{Temperatures of Phase Transformations}

Dilatometric measurements revealed that, when the steel under study was heated, $\alpha \rightarrow \gamma$ phase transformation ocurred in the range of $815\left(\mathrm{Ac}_{1}\right)$ to $863^{\circ} \mathrm{C}\left(\mathrm{Ac}_{3}\right)$ and was accompanied by a decrease in the specimen's length. These temperatures are in agreement with the reference data ${ }^{16)}$ for steels of similar composition. The progress of phase transformations on cooling depended on the rate temperature was changing with. When a specimen was cooled slowly with the furnace, pearlite transformation took place in the range of $780\left(\mathrm{Ar}_{1}\right)$ to $700^{\circ} \mathrm{C}\left(\mathrm{Ar}_{3}\right)$. Under accelerated cooling bainite transformation was observed in the range of 480 to $310^{\circ} \mathrm{C}$. Further increase in the cooling rate led to martensite transformation, which started at $50^{\circ} \mathrm{C}$. Besides the cooling rate, the temperature range of all $\gamma \rightarrow \alpha$ transformations depended on the maximum temperature the specimen was heated to before cooling. This effect originated evidently from dissolution of carbides in austenite that resulted in an increase in the concentrations of carbon and alloying elements in $\gamma$-phase and correspondingly in growth in its stability on cooling.

\subsection{High-temperature Mechanical Properties}

The temperatures of mechanical testing were chosen on the basis of the dilatometric data on the phase transformations. Specimens were tested in both ferrite-carbide and austenite-carbide states. In order to obtain the second one the specimens were heated above the $\mathrm{Ac}_{3}$ point to $890^{\circ} \mathrm{C}$, held for $5 \mathrm{~min}$ and then were cooled to the testing tempera-

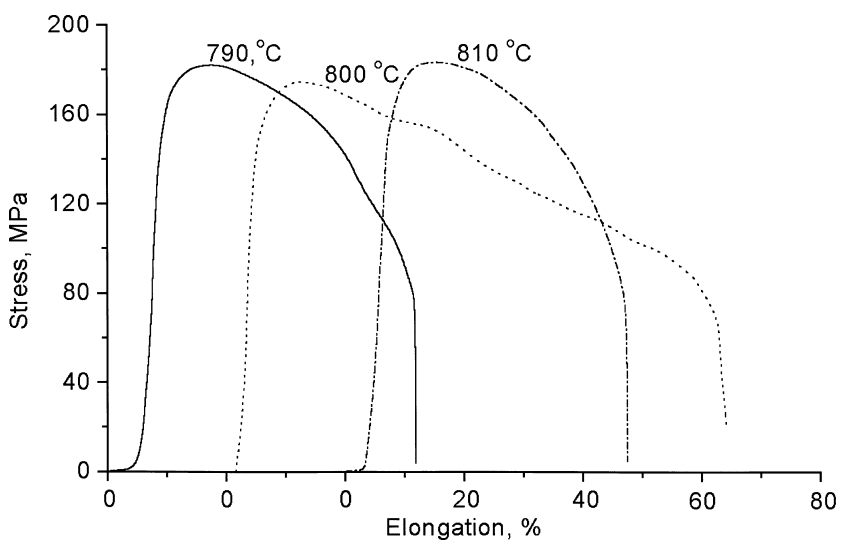

Fig. 2. Stress-strain curves of samples with austenite-carbide structure.

ture. The results are summarized in Fig. 1. Some stress-strain curves obtained while investigating specimens with the austenite-carbide structure are given in Fig. 2. The principal findings can be formulated as follows:

- The tensile strength and the yield stress of the steel with the ferrite-carbide structure reduce almost by half as temperature raises from 700 to $800^{\circ} \mathrm{C}$, while the characteristics of plasticity (relative elongation) somewhat grow;

- A sharp, almost twofold, increase in strength and some decrease in plasticity occur in going from the ferrite-carbide to the austenite-carbide state;

- The mechanical properties of the steel with the austenitecarbide structure are not monotonic functions of temperature. At $800^{\circ} \mathrm{C}$, that is at temperature only slightly above the starting point of $\gamma \rightarrow \alpha$ transformation on cooling, one can see minimums in the $\sigma_{0,2}$ versus $T$ and $\sigma_{\mathrm{B}}$ versus $T$ curves and a maximum in the $\delta=f(T)$ curve, the maximal value of elongation being almost two times higher than the values observed at lower and higher temperatures;

- Near the starting point of $\gamma \rightarrow \alpha$ transformation on cooling the stress-strain curves of the steel with the austenitecarbide structure exhibit waviness (Fig. 2).

\subsection{Microstructure and Phase Composition}

Figure 3 demonstrates the microstructure of the steel under investigation in the initial $(a, b)$ and rolled $(d, e)$ states as viewed through the scanning electron microscope. 
(a)

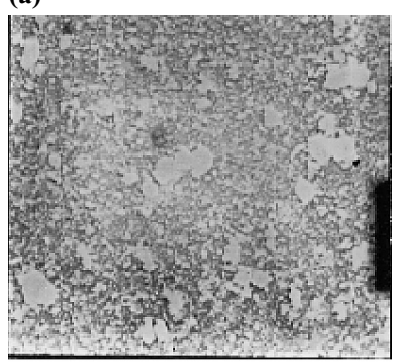

$10 \mu \mathrm{m}$

(c)

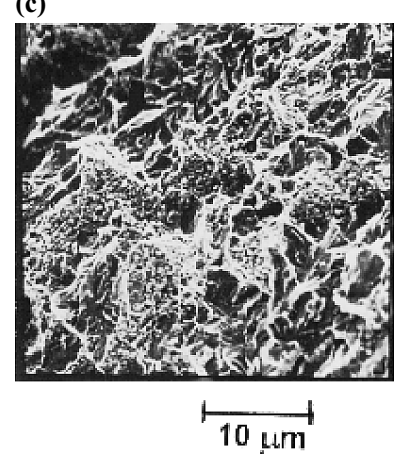

(e)

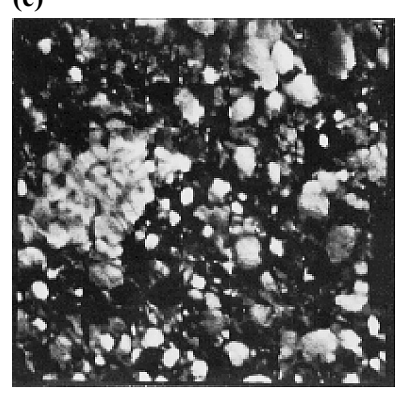

$\stackrel{10}{10 \mu \mathrm{n}}$ (b)

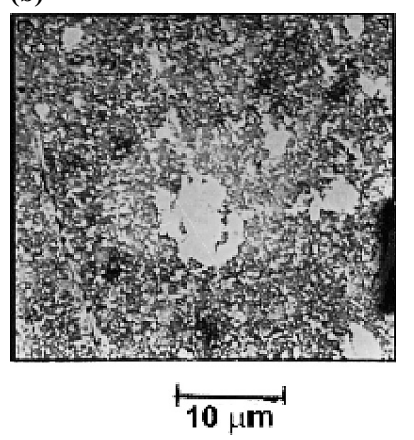

(d)

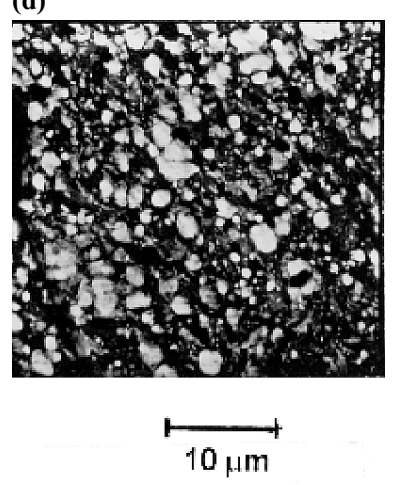

(f)

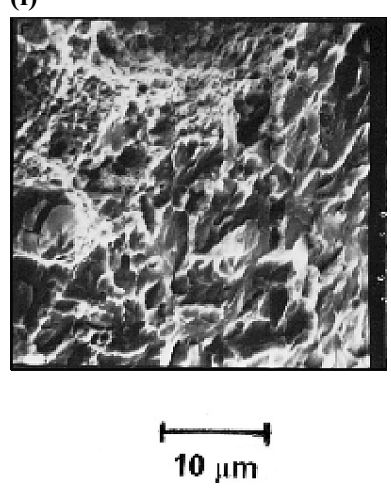

Fig. 3. Specific features of the steel under study in the initial $(a-c)$ and rolled $(d-f)$ states: $a, b, d, e-$ microstructure; c, $\mathrm{f}$-microrelief of fracture surfaces in the region of stable crack growth.

(a)

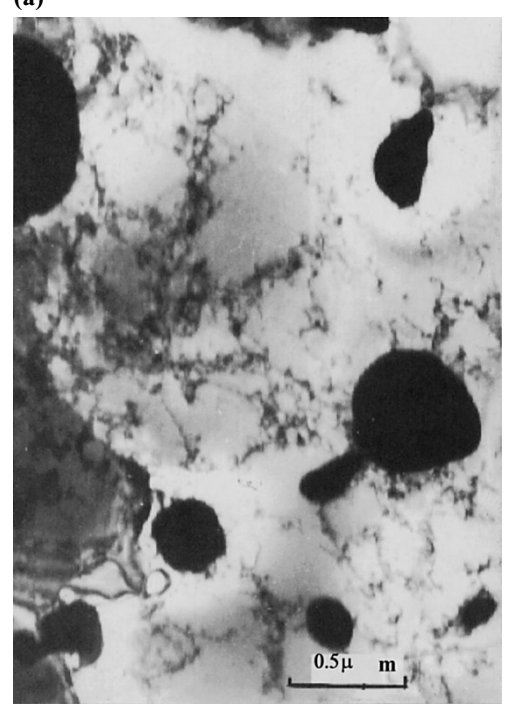

Granular pearlite with homogeneously distributed particles of cementite and other carbides is characteristic to both states. The microstructure of the steel in the initial state appears more coarse-grained with a wider scatter in the size of carbide particles. A closely similar, but more detailed, picture was revealed by the transmission electron microscopy. In the initial state the ferrite grains of granular pearlite were found to exhibit a dislocation pile-up pattern. The grain size attained 3-5 $\mu \mathrm{m}$ (Fig. 4). Volume fraction of carbides exceeded $10 \%$ and the size of carbide particles fell into the range of 0.1 to $10 \mu \mathrm{m}$, sometimes exceeding it. The nature of carbides was established through analysis of electron microdiffraction (Fig. 5). The coarse particles were found to be cementite, while fine ones-chromium and tungsten carbides. According to the results of the Auger spectroscopy the chemical composition of carbide particles that did not belong to cementite corresponded to $(\mathrm{Cr}, \mathrm{Fe}, \mathrm{W})_{7} \mathrm{C}_{3}$. After rolling the granular pearlite structure retained, but its characteristics changed (Fig 6(a)). The deformation reduced the diameter of ferrite grains to $1-3 \mu \mathrm{m}$ and led to formation of well-defined polygonal low-angle grain boundaries (Fig. 6(b)). Stacking faults appeared inside some carbide particles. The size of the carbides particles $(\sim 1 \mu \mathrm{m})$ became comparable, on the average, with that

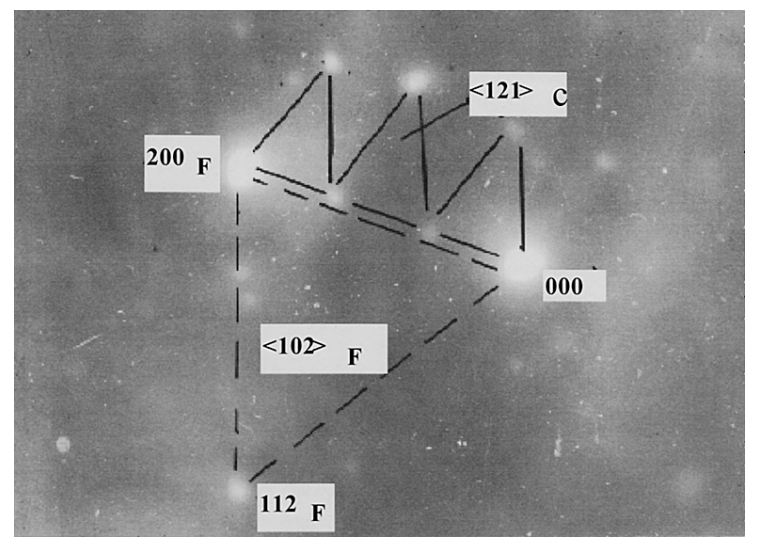

Fig. 5. Electron patterns of a ferrite grain (the zone axis $\langle 120\rangle_{\mathrm{F}}$ ) and from a cementite particle (the zone axis $\langle 120\rangle_{\mathrm{C}}$ ).

(b)

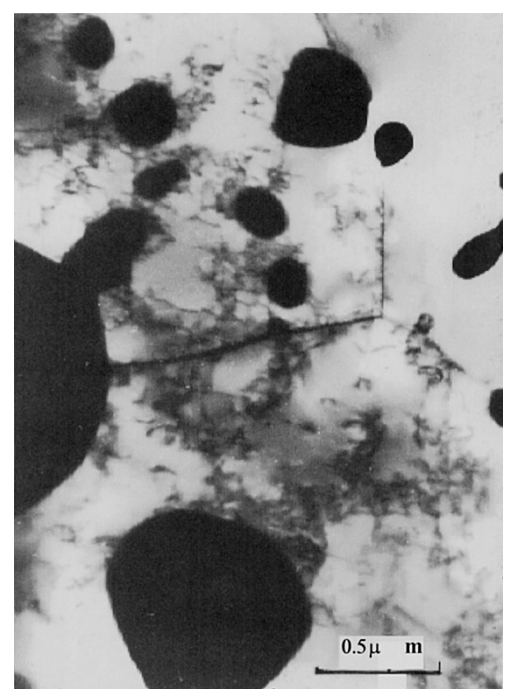

Fig. 4. Microstructure of the steel in the initial state: a-carbide particles and cellular dislocation substructure inside a ferrite grain; $b$ - triple joint of ferrite grain boundaries, cellular dislocation substructure inside a ferrite grain and coarse carbide particles. 
(a)

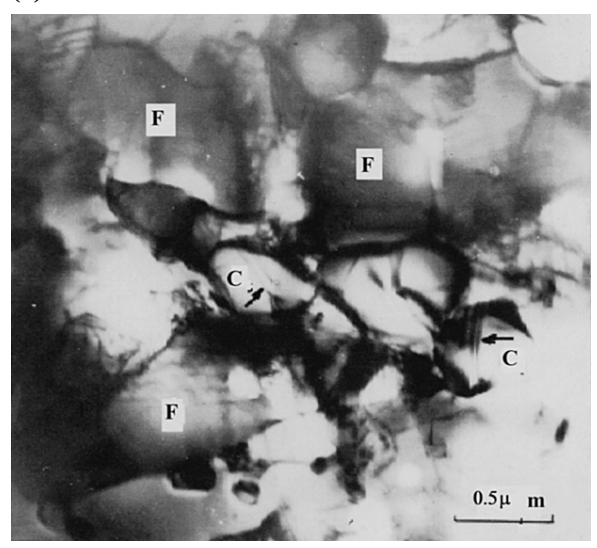

(b)

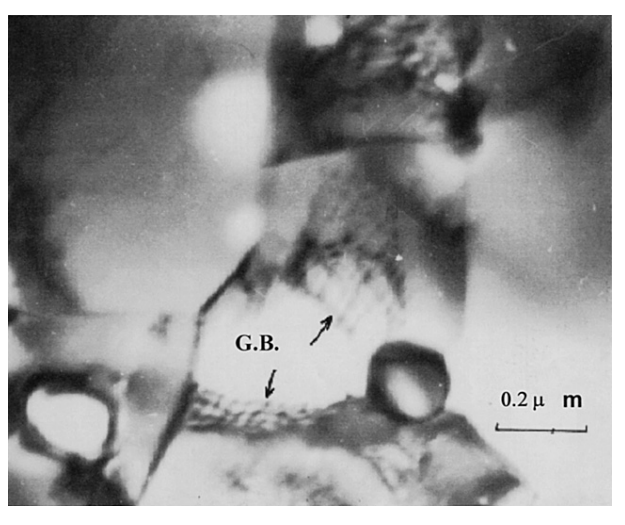

Fig. 6. Microstructure of the steel in the rolled state: a - fine grains of ferrite (F) and particles of cementite (C) and carbides of alloying elements, stacking faults in cementite being indicated by arrows; $b$ - low-angle grain boundaries (G.B.) - dislocation networks in ferrite grains.

of the ferrite grains and sub-grains. Thus, rolling at moderate temperatures combined with the high-speed heating resulted in formation of a fine-grained matrix with well-defined dislocation substructure and uniformly distributed carbides.

\subsection{Fracture Surfaces}

The typical structure of fracture surfaces are given in Figs. 3(c) and 3(f). The appearance of abundant facets of brittle cleavage having a lath pattern (Fig. 3(c)) demonstrate that the fracture of samples prepared from the steel in the initial state was basically brittle in character and occurred mainly across the grains. The fraction of segments, fractured plastically with formation of cellular structure, was about $20 \%$. A highly developed surface was formed in the process of fracture of the steel in the rolled state (Fig. 3(f)). It contained segments of cellular structure pointing to ductile fracture and facets of brittle cleavage in the equal proportion. Thus, the combination of the high-speed heating with rolling at moderate temperatures raised markedly the steel plasticity.

\section{Discussion}

The results of dilatometric measurements revealed that the steel under study was rolled near the temperature of $\alpha \rightarrow \gamma$ transformation, when it was in the ferrite-carbide state. If the elongation anomaly is abstracted for a while from the discussion, Fig. 1 allows conclusion that it is in this state near the $\mathrm{Ac}_{1}$ point the steel possesses properties best suited for rolling. Similar combination of strength and plasticity in the case of the austenite-carbide state is observed $150-200^{\circ} \mathrm{C}$ higher. A small enough increase in the rolling temperature may result in substantial growth in strength because of formation of austenite, while with decreasing temperature the yield stress grows fast owing to the strong temperature dependence of the steel mechanical properties. In other words, both overheating and overcooling impair the conditions of rolling so that the temperature of steel should be maintained quite accurately. It is evident that ohmic heating provides the most efficient means of temperature control. Thus the stability of the ferrite-carbide structure up to $815^{\circ} \mathrm{C}$ is the major factor that deter-

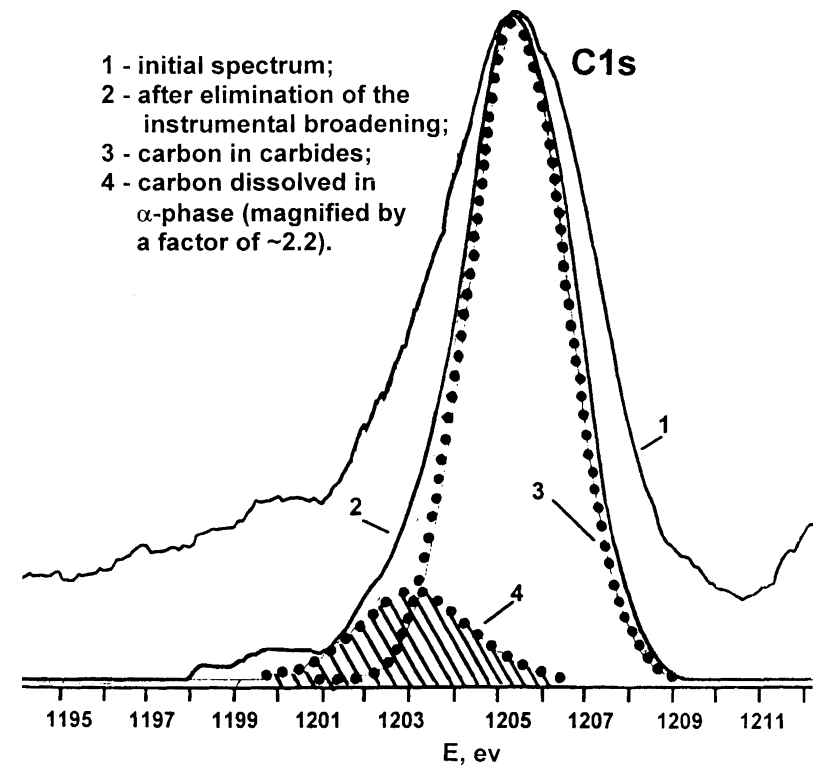

Fig. 7. The $\mathrm{C} 1 \mathrm{~s}$ carbon line of the X-ray photoelectron spectrum obtained from the surface of a rolled specimen: 1 - initial spectrum; 2 - after elimination of the instrumental broadening; 3 - carbon in carbides; 4 - carbon dissolved in $\alpha$ phase (magnified by a factor of $\sim 2.2$ ).

mines the steel plasticity high enough for rolling at moderately low temperatures.

This type technological feasibility arises from the high $\mathrm{Ac}_{1}$ temperature of the steel under study that exceeds the corresponding point for carbon and low-alloyed steels by $\sim 100^{\circ} \mathrm{C}$. This fact suggests that almost all carbon should be bound in carbides so that its concentration in $\alpha$-solid solution is rather low. To either validate or disprove this conclusion, chemical analysis of the $\alpha$-solid solution was carried out by the ESCA technique. The research was carried out using an ESCALAB MK 2 spectrometer and monochromatic $\mathrm{AlK} \alpha$ radiation $(h v=1486.6 \mathrm{eV})$. The instrumental broadening did not exceed $0.6 \mathrm{eV}$.

The C1s carbon line of the X-ray photoelectron spectrum obtained from the surface of a specimen in the rolled state is shown in Fig. 7. The peak is seen to correspond to the emitted electrons kinetic energy equal to $1205.5 \mathrm{eV}$. In the case of pure graphite this peak should be positioned at $1203.0 \mathrm{eV}$, if the energy of X-ray radiation used for the 
analysis is taken into account. ${ }^{17-19)}$ Thus the spectrum line under consideration is shifted to the higher kinetic energy, which is typical for carbides. ${ }^{20,21)}$ As the steel microstructure was rather dispersed, it was supposed that the intensity of this spectrum line accounted for the total carbon concentration in the steel. After elimination of the instrumental broadening, the line was divided into two parts: one, coming from the carbon dissolved in $\alpha$-iron, and the other, originating from the carbon that was the part of the carbide phases. The procedure ${ }^{18,19,22)}$ was used for the purpose. The dissolved carbon atoms practically do not react with Fe, so that the position of the corresponding spectrum line was assumed to coincide with that characteristic to pure graphite. On the other hand, as the mole carbon concentrations in the carbides observed in the steel were rather close, it was assumed that the second type $\mathrm{C}$ atoms could be described by the same spectrum line situated at $1205.5 \mathrm{eV}$. The part corresponding to the dissolved carbon was found to be $\sim 17$ less intensive. Taking into account the fraction of carbides in the steel, this allowed assessment of the carbon concentration in the $\alpha$-phase as $0.035 \mathrm{~mol} \%(0.0075 \mathrm{wt} \%)$.

Another important feature of rolling in the ferrite-carbide state lies in the fact that this type treatment is not accompanied by grain growth. On the contrary, it results in formation of a fine-grained matrix with well-defined dislocation substructure, uniformly distributed carbide and higher plasticity.

We now turn to discussion of the non-monotonic temperature behavior of the mechanical properties of the steel with the austenite-carbide structure. It suggests that an effect of the TRIP type might occur in the course of mechanical testing at temperatures near the $\mathrm{Ar}_{1}$ point. There are several arguments in favor of this hypothesis. First, the anomalous temperature functions of the mechanical properties characteristic to the austenite-carbide state (Fig. 1) are in close similarity with the $\sigma_{0.2}, \sigma_{\mathrm{B}}$ and particularly $\delta$ versus temperature curves that are typical for steels with the TRIP-effect. ${ }^{23,24)}$ Second, the temperature range, where the anomaly in the mechanical properties was observed, is rather narrow like the interval of the TRIP-effect appearance. ${ }^{23,24)}$ Third, the waviness inherent in the stress-strain curves of the steel in the austenite-carbide state near the $\mathrm{Ar}_{1}$ point (Fig. 2). Forth, the sharp growth in plasticity occurred only while testing specimens with the austenite-carbide structure. The obvious explanation of the last fact is that stretching assists the progress of $\gamma \rightarrow \alpha$ transformation because it is accompanied by an increase in volume. On the contrary, the ferrite-to-austenite transformation leads to a decrease in volume and, therefore, stretching retards its development. That is why no signs of the similar effect were found while tensile testing samples in the ferrite-carbide state. In the latter case the TRIP-type effect is expected under compression. Precisely this kind deformation occurs in the process of rolling and it seems safe to expect an increase in plasticity of any steel with ferrite structure if it is rolled near the temperature of $\alpha \rightarrow \gamma$ transformation.

After the high-speed heating, just before rolling began, the temperature of the steel under consideration differed from the $\mathrm{Ac}_{1}$ point by $\sim 25^{\circ} \mathrm{C}$. Deformation should certainly raise the metal temperature. The expected increment can be estimated under assumption that heating occurs adiabati- cally, that is the work of deformation, $w$, transforms completely into heat. If the deformation rate dependence of tensile strength is neglected, the increase in temperature can be assessed from the following equation

$$
\Delta T=w / C_{\mathrm{P}} m,
$$

where $C_{\mathrm{P}}$ and $m$ are the metal heat capacity and mass. For simplicity a sample in the form of cube with edge $l_{\mathrm{o}}$ will be considered. In this case

$$
w=\sigma_{B} S \Delta l \text { and } m=l_{\mathrm{o}}^{3} \rho
$$

where $S$ is the area the deformation force is applied to, $\Delta l$-deformation equal in our case to $0.43 l_{\mathrm{o}}$ and $\rho$-density of steel. According to Fig. 1 at $790^{\circ} \mathrm{C} \sigma_{\mathrm{B}} \approx 100 \mathrm{MPa}, S$ can be equated to the area average between the side of the sample before and after deformation, the latter being found under the condition that the sample volume remains unchanged in the course of deformation. Calculations carried out under assumption that $C_{\mathrm{P}}$ and $\rho$ of the steel under consideration did not differ much from the heat capacity ${ }^{25)}$ and density $^{26)}$ of pure iron resulted in $\Delta T \approx 12$ centigrade. Thus the temperature of the steel in the process of rolling is close enough to the $\mathrm{Ac}_{1}$ point, so that the rather high steel plasticity that allows rolling at relatively low temperatures can be partly induced by $\alpha \rightarrow \gamma$ transformation.

\section{Conclusions}

Phase transformations, high-temperature mechanical properties of a tool steel $(1.11 \mathrm{wt} \% \mathrm{C}, 6.05 \mathrm{wt} \% \mathrm{Cr}, 0.72$ wt $\%$ V, 1.20 wt $\%$ W, 0.16 wt $\%$ Si, 0.25 wt $\%$ Mn, $0.018 w t \%$ $\mathrm{S}$ and $0.02 \mathrm{wt} \%, \mathrm{P}$ ) as well as its structure before and after rolling were studied with the aim of clarifying regularities that allow rolling high-carbon highly-alloyed steels with rather high degrees of deformation at moderately low temperatures $\left(\sim 800^{\circ} \mathrm{C}\right)$. The obtained results revealed the following.

(1) The temperature range of rolling lies in the neighborhood of the temperature interval, where phase transitions connected with $\alpha \leftrightarrow \gamma$ transformation of iron take place. The steel is subjected to deformation when it is in the ferrite-carbide state.

(2) According to the dilatometric measurements $\alpha \rightarrow \gamma$ transformation in the steel under study starts at $815^{\circ} \mathrm{C}$, which is $\sim 100^{\circ} \mathrm{C}$ higher than $\mathrm{Ac}_{1}$ point of carbon and construction steels. The cause of the elevated start temperature lies, as was ascertained by X-ray photoelectron spectroscopy, in the low concentration of carbon dissolved in $\alpha-$ Fe because the steel contains sufficient amount of strong carbide-forming elements.

(3) In the neighborhood of the temperature range of the phase transformation the steel possesses significantly higher plasticity and lower strength when it is in the ferritecarbide state. This suggests that higher plasticity of $\alpha$ phase and its stability up to temperatures exceeding $800^{\circ} \mathrm{C}$ are the major factors that make possible rolling at moderately low temperatures.

(4) The mechanical properties of the steel in the austenite-carbide state are not monotonic functions of temperature. Minimums in the $\sigma_{0,2}$ versus $T$ and $\sigma_{\mathrm{B}}$ versus $T$ curves and a maximum in the $\delta=f(T)$ curve were observed 
slightly above the starting point of $\alpha \leftrightarrow \gamma$ transition on cooling. The non-monotonic behavior of the mechanical properties suggests that an effect of the TRIP type occurred in the process of testing of the steel under study. This allowed speculation that the TRIP-type effect might also contribute into plasticity of high-carbon highly-alloyed steels in the course of rolling at moderate low temperatures.

(5) Both increasing and decreasing temperature impair the conditions of rolling, but for various reasons: a rise in temperature leads to formation of more strong and less plastic austenite, while a fall affects the mechanical properties through their strong temperature dependence. This feature requires quite accurate maintenance of the steel temperature in the process of rolling. In this regard the ohmic heating offers considerable advantages over other ways of heating.

(6) Combination of the high-speed heating with rolling at moderate temperatures results in formation of a finegrained matrix with well-defined dislocation substructure and uniformly distributed carbide and in higher plasticity.

\section{Acknowledgement}

The authors are grateful to A. Edneral, V. Isotov, A. Kovalev and D. Wainstain for performance of measurements and helpful discussions.

\section{REFERENCES}

1) E. Houdremont: Handbuch der Sonderatahlkunder, B.1-2, SpringerVerlag, Berlin, (1956), 950.

2) Yu. A. Geller: Tool Steels, 5th ed., Metallurgiya, Moscow, (1983), 224, 393. (in Russian)

3) N. V. Pasetchnik: Ferrous Metallurgy, Bulletin \#2, Chermetinformatsiya, Moscow, (1996), 52. (in Russian)

4) N. V. Pasetchnik: Steel Technology International 1997/1998, Sterling Publication Ltd., London, (1998), 117.

5) A. Sauveur: Stahl Eisen, 44 (1924), 1040.

6) E. Houdremont and P. Kallen: Stahl Eisen, 47 (1927), 546.
7) M. M. Vratskii and N. I. Frantsevitch: Steel, No. 7-8 (1932), 36; No. 4 (1933), 24. (in Russian)

8) E. Scheil: Zf. Anorg. Chem., 207 (1932), 21.

9) G. Wasserman: Arch. Eisenhüttenwes., 6 (1933), 347; 9 (1936), 89; 10 (1937), 321.

10) M. G. Losinski and I. S. Semenova: Acta Metall., 7 (1959), 209.

11) G. W. Greenwood and R. H. Johnson: Proc. R. Soc., (London) A, 283 (1965), 403.

12) B. P. Pribylov, P. G. Katsev and V. P. Eskin: Machine-Building Technology, No. 11-12 (1967), 26. (in Russian)

13) A. P. Gulyaev and L. M. Sarmanova: Metallography and Thermal Treatment of Metals, No. 1 (1969), 2. (in Russian)

14) A. P. Gulyaev: Superplasticity of Steels, Metallurgiya, Moscow, (1982), 17. (in Russian)

15) E. I. Estrin: Zavodskaya Laboratoriya, 34 (1968), 1131.

16) L. A. Potsdnyak: Tool Steels, Metallurgiya, Moscow, (1977), 46. (in Russian)

17) T. A. Carlson: Photoelectron and Auger Spectroscopy, Plenum Press, New York, (1975).

18) B. D. Rather and D. G. Castner: Surface Analysis: The Principal Techniques, ed. by J. C. Vickerman, John Wiley and Sons, Chichester, (1997), 43

19) A. I. Kovalev and G. V. Chsherbedinsky: Modern Techniques of Research of Metals and Alloys Surfaces, Metallurgiya, Moscow, (1989), 37. (in Russian)

20) L. Ramqvist, K. Hamrin, G. Johansson, U. Gelins and C. Nordling: $J$. Phys. Chem. Solids, 31 (1970), 2669.

21) L. Ramqvist, K. Hamrin, G. Johansson, A. Fahlman and C. Nordling: J. Phys. Chem. Solids, 30 (1969), 1835.

22) V. I. Nefedov: X-ray Photoelectron Spectroscopy of Chemical Compounds, Khimiya, Moscow, (1984), 37. (in Russian)

23) V. F. Zackey, E. R. Parker, D. Fahr and R. Busch: Trans. Am. Soc. Met., 60 (1967), 252.

24) I. Ya. Georgieva: Itogi Nauki i Tekhniki, Metallovedenie i Termicheskaya Obrabotka (Summary of Scientific and Technical Research, Physical Metallurgy and Thermal Treatment), v.16. VINITI, Moscow, (1982), 69.

25) JANAF Thermochemical Tables, 3rd ed., J. Phys. Chem. Ref. Data, (1985), 14

26) C. I. Smithells: Metals Reference Book, Butterworth and Co. Ltd., London, (1976), 437. 